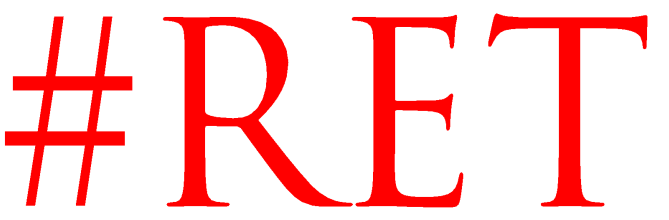

Revista Española de la Transparencia

Núm. 13. Segundo Semestre. Julio-diciembre de 2021, pp. 173-191

ISSN 2444-2607. Www.revistatransparencia.com

DOI: https://doi.org/10.51915/ret.182

\title{
El abuso del secreto de Estado en la ocultación de las actuaciones ilegítimas de los poderes públicos: el caso español
}

José Antonio Sendín Mateos1

Universidad de Salamanca

España

ORCID: 0000-0002-8740-2752

RECIBIDO: 14 de abril de 2021 ACEPTADO: 5 de septiembre de 2021

RESUMEN: El tema de este trabajo son los usos indebidos que a veces hacen los poderes públicos de los secretos de Estado -en particular en nuestro país-, a fin de ocultar actividades ilegítimas. Tras referirme a las condiciones para el uso correcto de los secretos de Estado, y explicar críticamente los defectos de la regulación española, mencionaré ciertos abusos y ejemplos de mala praxis en las actuaciones del órgano con competencia para la clasificación de materias. Asimismo, aludiré a los términos en los que la Ley de transparencia de 2013 amplia las materias a las que se permite restringir el libre acceso, y haré una referencia al caso de los "papeles del CESID", que fue el ejemplo más evidente de la utilización de los secretos de Estado para encubrir actos gubernamentales ilegítimos. Para concluir, enumeraré los cambios que sugiere, en la regulación vigente de los secretos de Estado, la Proposición de ley de reforma de la Ley de secretos oficiales, presentada en el Congreso de los Diputados por el Grupo Parlamentario Vasco (EAJ-PNV).

PALABRAS CLAVE: Secreto de Estado, publicidad, transparencia, derecho de acceso a la información.

1 Profesor ayudante doctor del Área de Filosofía del Derecho de la Universidad de Salamanca, doctor cum laude con la tesis doctoral "La filosofia moral de Hans Kelsen", premio extraordinario de doctorado y premio de doctorado del Colegio Oficial de Doctores y Licenciados en Filosofía y Letras y en Ciencias de Valladolid, coordinador académico del Máster en Teoría del Derecho y Argumentación Jurídica de la USAL, subdirector de la Clínica Jurídica de Acción Social (CJAS), donde coordina la línea de Memoria Democrática. 
CONTENIDOS: 1. Introducción. - 2. Condiciones del uso correcto de los secretos de Estado. - 3. Valoración de la regulación española de los secretos de Estado. - 4. Algunos mecanismos de ocultación en el derecho español. - 5. Breve mención a los "papeles del CESID". - 6. A modo de conclusión: la proposición de ley de reforma de la Ley de Secretos Oficiales. -Bibliografía.

NOTA: Trabajo realizado en el marco del proyecto de investigación PID2019106904RB-100 (Construcción de derechos emergentes. Debates para la fundamentación de nuevos parámetros de constitucionalidad), financiado por la Agencia Estatal de Investigación.

\section{The abuse of the state secret in the concealment of the illegitimate actions of the authorities: the Spanish case}

\section{ABSTRACT:}

This article deals with the improper use that the authorities sometimes make of state secrets - particularly in Spain-, in order to conceal illegitimate activities. After referring to the requirements for the correct use of state secrets, and once I have critically explaining the deficiencies of the Spanish regulation, I will mention certain abuses and examples of malpractice in the actions of the organ with authority for the classification of determined issues. I will also allude to the terms in which the Transparency Act of 2013 broadens the matters to which it is permitted to restrict free access, and I will make a reference to the case of "CESID papers", which was the most obvious example of the use of state secrets in order to conceal illegitimate governmental acts. To conclude, I will list the changes proposed, in the current regulation of state secrets, by the Bill for the reform of the Law on Official Secrets, put submitted in the Chamber of Deputies by the Basque Parliamentary Group (EAJ-PNV).

KEYWORDS: State secret, publicity, transparency, right of access to information. 


\section{Introducción}

El objeto de este trabajo ${ }^{2}$ es examinar algunos usos indebidos que a veces hacen los poderes públicos de los secretos de Estado, buscando ocultar actividades ilegítimas, para lo cual voy a fijarme en el caso español.

Los secretos de Estado son una manifestación de lo que en teoría política se denomina la "razón de Estado"3. Los gobiernos deberían recurrir a esos secretos únicamente en casos excepcionales, pues en cualquier Estado constitucional y democrático la publicidad de los actos del poder han de ser la regla general, mientras que la utilización de los secretos de Estado solo se justifica para salvaguardar determinados bienes e intereses vitales. El problema es que desde el poder político y otros organismos (políticos y militares) los secretos de Estado se han utilizado habitualmente con intenciones que no siempre son honorables, pues estos instrumentos han permitido ocultar a los ojos de la opinión pública tanto acciones reprobables como informaciones que pueden ser comprometedoras para quienes ejercen directamente el poder $u$ orbitan alrededor. Es obvio que en estas ocasiones la pretensión no es ya asegurar la continuidad del Estado, sino servirse de los secretos de Estado para proteger al gobierno de turno o a algún otro ente con poder, tanto si es público como privado. Evidentemente, de lo que se trata es de evitar que ciertas informaciones lleguen a ser conocidas por la ciudadanía y provoquen escándalo e irritación.

Así pues, es fácil de entender que, como consecuencia de una utilización abusiva de los secretos de Estado, pueda ponerse en entredicho la honestidad -en términos morales y políticos- de los gobiernos. Sus actuaciones, y las de quienes hacen uso del poder en los diferentes estratos de la administración, deberian respetar en todo caso las prescripciones y cautelas legales para hacer un uso irreprochable de los secretos de Estado. Si estos se utilizan observando estrictamente las restricciones y cauces jurídicamente establecidos, realizarán una función instrumental (Sánchez Ferro, 2006: 11) cuya relevancia social es indiscutible, pues su pretensión es garantizar, dentro de los estándares de aceptabilidad política y moral característicos de un Estado democrático, una serie de intereses comunes que son esenciales para la continuidad del mismo, como la seguridad nacional y la defensa. Con ese objetivo, y para refrendar que los secretos de Estado se utilizan correctamente, estos deben someterse a algún control institucional, que puede ser jurisdiccional o legislativo. Si se cumplen estas previsiones, no hay motivo para dudar de la compatibilidad de los

\footnotetext{
2 En mi artículo Sendín (2020) realicé un estudio más extenso del concepto de secreto de Estado y de algunas de sus implicaciones. En esta perspectiva, la obra de referencia es el libro de Susana Sánchez Ferro (2006).

${ }^{3}$ Un estudio muy recomendable sobre la razón de Estado y el uso que a menudo se hace de los secretos de Estado como un recurso a disposición del poder es el libro de Rafael del Águila (2000).
} 
secretos de Estado con las dinámicas propias de la política democrática, ni para negarles un lugar y una función en los Estados constitucionales actuales.

La legislación española en materia de secretos de Estado trata de proteger los intereses comunes de la seguridad nacional y la defensa en sintonía con las exigencias operativas mencionadas. No obstante, como luego explicaré de forma más detallada, la regulación vigente en nuestro pais ha de ser valorada negativamente. La Ley 9/1968 de 5 de abril, sobre secretos oficiales ${ }^{4}$ (LSO) y su Reglamento ${ }^{5}$-dos vestigios de la legislación del franquismo que aún perviven en la actualidad- autorizan a clasificar aquellas materias cuyo conocimiento pueda acarrear un grave riesgo para los intereses fundamentales de la Nación y supongan una amenaza para la defensa nacional, la paz exterior y el orden constitucional. Servirse de esta posibilidad no solo es aceptable, sino que en cualquier Estado democrático la salvaguarda de estos bienes es percibida como un objetivo loable e incluso una obligación de las autoridades gubernamentales.

Ahora bien, la normativa española no está exenta de problemas -algunos especialmente graves- en lo que atañe al control de la declaración de secretos de Estado y los acuerdos de clasificación de materias. Por un lado, sigue habiendo un importante debate doctrinal sobre cuál debería ser la manera de efectuar el control jurisdiccional de esos secretos. La cuestión sigue sin ser del todo pacífica, a pesar de que hay un consenso de que en el caso, bien conocido, de los "papeles del CESID" -que se hizo público a mediados de los años noventa- la labor del órgano competente -la Sala $3^{\text {a }}$ del Tribunal Supremo- fue muy meritoria. Por otro lado, una característica del modelo español es que los secretos de Estado pueden prolongarse a lo largo del tiempo de forma que no caducan y su vigencia parece indefinida, habida cuenta de que no se regulan plazos para que las materias secretas sean desclasificadas de forma automática. Por este motivo, en tanto que esas materias no sean desclasificadas a través de una decisión acordada por la autoridad competente, la única posibilidad de acceder a ellas es mediante un permiso especial. En nuestro sistema esto también supone una seria dificultad, porque la autoridad que tiene potestad exclusiva para tomar decisiones sobre la desclasificación de materias secretas es la misma que ejerce la competencia de clasificación, a saber: el Pleno del Consejo de Ministros. Teniendo todo esto en cuenta, no ha de sorprendernos que España se pueda considerar un país de secretos "eternos", en el que estos muestran una propensión casi natural a extenderse sine die a lo largo del tiempo.

\footnotetext{
${ }^{4}$ BOE de 6 de abril de 1968. Fue reformada por la Ley 48/1978, de 7 de octubre, por la que se modifica la Ley de 5 de abril de 1968, sobre secretos oficiales (BOE de 11 de octubre de 1978). Los comentarios de Pilar Cousido (1995) son muy útiles para obtener una visión panorámica de la regulación española vigente.

5 Aprobado por Decreto 242/1969, de 20 de febrero, por el que se desarrollan las disposiciones de la Ley 9/1968, de 5 de abril, sobre secretos oficiales (BOE de 24 de febrero de 1969).
} 
Cabría pensar que la aprobación de la Ley 19/2013, de 9 de diciembre, de transparencia, acceso a la información pública y buen gobierno (LTBG), fue una ocasión inmejorable para solucionar algunas de las carencias de la legislación sobre secretos oficiales. Sin embargo, fue una ocasión perdida. Aunque, ciertamente, esta ley imponía una obligación de transparencia a los órganos de las administraciones, por otro lado, y de forma paradójica, establecía restricciones adicionales al conocimiento de algunas materias, sobrepasando incluso las previsiones de la vigente LSO. Esto suponía un incremento notable del volumen de informaciones que podrian mantenerse apartadas del dominio público, impidiendo o haciendo muy difícil su conocimiento.

La problemática que rodea a la regulación española de los secretos de Estado es una cuestión de máxima actualidad y que desde hace unos años ha reclamado especial atención. En particular, después de que en la XII legislatura el Grupo Parlamentario Vasco (EAJ-PNV) en el Congreso de los Diputados presentara una Proposición de ley de reforma de la LSO. Es verdad que al final esta no fue aprobada y caducó al concluir dicha legislatura anticipadamente 6 . Sin embargo, en mi opinión no hay duda de que nos encontramos ante la tentativa más consistente de reformar la trasnochada normativa española sobre secretos oficiales. El Grupo Vasco -muy tenaz- presentó una vez más la Proposición de ley en la XIII legislatura ${ }^{7}$-con la misma suerte adversa- y en la actual XIV legislatura ${ }^{8}$. Si la tramitación en el Congreso de los Diputados fuera más acelerada, y el contenido de las enmiendas propuestas por otros grupos de la cámara fuera similar al de las que se presentaron en la XII legislatura, por fin se podría aprobar una reforma de la LSO que, a mi modo de ver, incluiría novedades muy significativas. Una particularmente interesante sería la previsión de un sistema de plazos para desclasificar materias de forma automática. No obstante, como explicaré al final del trabajo, las últimas informaciones arrojan nueva incertidumbre sobre el recorrido parlamentario de la Proposición de ley y hacen presagiar un futuro incierto.

En adelante daré cuenta de las siguientes cuestiones: (i) realizaré una serie de consideraciones a propósito de ciertas exigencias que deben observarse para que el uso que se haga de los secretos de Estado sea irreprochable; (ii) daré cuenta de los aspectos más característicos de la regulación española, que valoraré criticamente; (iii) llevando la exposición al punto que más me interesa, cuáles son las

\footnotetext{
${ }^{6}$ El recorrido de la Proposición de ley en el Congreso de los Diputados fue dificultoso, pues esta fue paralizada en el trámite de enmiendas durante una larga temporada. Cuando este fue superado el 20 de marzo de 2018, después de que el plazo fuera prorrogado hasta en cuarenta y dos ocasiones, pareció un buen presagio que hizo concebir esperanzas. Lamentablemente, el final de la legislatura llegó cuando el texto se encontraba pendiente del informe de la Comisión Constitucional, lo que provocó su caducidad. Ese mismo desenlace ya se había producido en la legislatura anterior -la número XI-, que finalizó sin que en el debate de investidura se otorgara confianza a un Presidente del Gobierno.

${ }^{7}$ Boletin Oficial de las Cortes Generales (BGCG), Serie B, 38-1, 25/06/2019.

${ }^{8}$ BGCG, Serie B, 31-1, 17/01/2020.
} 
implicaciones que tiene la utilización de los secretos de Estado soslayando los límites materiales y legales, para lo cual pondré el foco en ciertos abusos o malas prácticas que se han aplicado en nuestro país; (iv) una referencia al caso de los "papeles del CESID", que fue el ejemplo más evidente y más grave del uso indebido de los secretos de Estado en la historia reciente española; y (v) finalmente, cuáles son los avances más significativos que se plantean en la Proposición de ley del Grupo Vasco y cuál es el horizonte que se vislumbra en el régimen de los secretos de Estado en nuestro ordenamiento jurídico.

\section{Condiciones del uso correcto de los secretos de Estado}

Como sostiene Susana Sánchez Ferro (2006:18), los secretos de Estado deben utilizarse solo en casos excepcionales, limitándose al aseguramiento de unos bienes e intereses concretos, que son vitales para salvaguardar el Estado y garantizar su continuidad ${ }^{9}$. Esos bienes son la seguridad y la defensa. Más allá de la pretensión de protegerlos, es difícil que los secretos de Estado puedan ser compatibles con las dinámicas propias de los Estados constitucionales. En plena sintonía con estas afirmaciones, Aragón (2006: XIX) señala que los secretos de Estado han de operar «como rigurosa excepción a la regla general de publicidad», y satisfaciendo unas condiciones que este autor califica como "exigentes". Con ello se trata de que el empleo de los secretos de Estado sea algo residual, reservado a unas pocas ocasiones excepcionales. Para lograrlo, su regulación legal debe encaminarse a evitar que la práctica de recurrir a los secretos de Estado adquiera carácter de regla general (Wilkinson, 2007: 89).

Un rasgo de los Estados democráticos y constitucionales actuales es que tratan de hacer efectiva la pretensión de hacer "visibles" los actos de quienes ejercen el poder, de modo que no escapen a la vigilancia de la opinión pública. El problema, como ha observado Norberto Bobbio (1985: 20; 1986: 23 y 65), es que junto a la visibilidad que tienen muchas expresiones del poder estatal, existe un Estado y un poder cuyas actuaciones tratan de mantenerse ocultas, esto es, un poder "invisible". Bobbio recuerda que el nacimiento de la democracia se explica precisamente por la necesidad de que cualquier ejercicio invisible del poder sea extirpado de la vida pública. El ideal que se persigue es el de un "poder sin máscaras", cuyos actos sean públicos y transparentes y no dejen margen a los arcana imperii que caracterizan las políticas autocráticas (Bobbio, 1985: 21; 1986: 23).

Que la publicidad es un rasgo definitorio de los regímenes democráticos fue subrayado también, con el mismo énfasis, por Hans Kelsen (1968: 1763; 2006: 234). En cambio, el oscurantismo y el ejercicio opaco del poder es algo propio de las

\footnotetext{
${ }^{9}$ Según Manuel Aragón (2006: XVIII), los secretos de Estado son uno de los problemas más delicados a los que se ha enfrentado el constitucionalismo, «pues pocos asuntos, como éste, ponen de manifiesto la tensión entre la necesidad de preservar el Estado, sin cuya existencia no cabe la convivencia política, y la necesidad de controlar a ese mismo Estado, sin lo cual esa convivencia no estaria basada en la libertad». Si ese equilibrio se rompiera, estaría en riesgo la propia supervivencia del Estado.
} 
formas de gobierno autocráticas y totalitarias. En las dictaduras es habitual practicar la ocultación de ciertas actuaciones de dirigentes y cargos públicos, a fin de reducir a la mínima expresión los riesgos que para el poder podría suponer el ejercicio de un control jurídico o político eficaz, capaz de convertir las decisiones adoptadas a espaldas de la opinión pública en objeto de crítica. De esta manera, la publicidad es elevada a la categoría de valor democrático fundamental, y se admite que el sistema político será tanto más saludable y gozará de más calidad cuanto mayor sea el avance en la satisfacción de dicho valor.

Fue en la etapa de la Ilustración cuando la pretensión de institucionalizar la publicidad como un valor democrático fundamental dio sus primeros pasos. Ya entonces Beccaría era partidario de que el empleo de los secretos de Estado quedara reservado a situaciones excepcionales, a fin de evitar que estos pudieran servir de parapeto a cualquier ejercicio deshonesto del poder ${ }^{10}$.

En un sentido muy parecido, también Kant situó la publicidad como un valor fundamental en las actuaciones estatales y en el desempeño de las actividades de gobierno. En el apéndice de Hacia la paz perpetua enunció el principio-que muestra una doble vertiente moral y jurídica- de que «Todas las acciones referidas al derecho de otros seres humanos que no sean compatibles con la publicidad son injustas» (Kant, 2018: 120). En su opinión, este sería el "principio trascendental" del Derecho público, que serviría como marco para valorar como morales o inmorales los actos del poder que únicamente pueden realizarse a condición de que se hagan en secreto, puesto que, si se consumaran a la vista de todos, inducirían el rechazo de la ciudadanía, avivando reacciones desfavorables.

Ahora bien, independientemente de las valoraciones -en términos éticos- que hagamos de las expresiones invisibles del poder, no puede perderse de vista que en todos los Estados -incluidos los Estados constitucionales actuales- perviven y se utilizan los secretos de Estado. Esto es algo que Bobbio tiene muy presente al subrayar que, a pesar de que desde la idealidad democrática es exigible que el ejercicio del poder sea visible, los secretos de Estado también pueden encontrar justificación en situaciones de excepcionalidad. Para ello, es necesario observar una exigencia fundamental:

«La publicidad es la regla, el secreto es la excepción, y en todo caso es una excepción que no puede aminorar la regla, ya que el secreto está justificado al igual que todas las medidas excepcionales [...] solamente si está limitado en el tiempo» (Bobbio, 1986: 67).

La temporalidad es una condición que deberían cumplir los secretos de Estado para justificarse. Desde esta perspectiva, hay dos modelos básicos de tratamiento de los secretos: (i) los sistemas que regulan plazos para la desclasificación automática de

10 Javier de Lucas (1990: 138) recuerda que la publicidad era invocada para impedir que se usara el secreto de Estado como «el más firme escudo de la tiranía». 
las materias secretas al transcurrir un cierto número de años, y (ii) los sistemas en los que para que se produzca la desclasificación se requiere una decisión adoptada por un órgano que tiene atribuida esa competencia. A mi modo de ver, los primeros son netamente preferibles, pues ofrecen más garantías para la salvaguarda del valor de la publicidad. Desgraciadamente, en España tenemos un sistema del segundo tipo, en contraste con los que se utilizan en paises de nuestro entorno en los que lo común es prever un término final para desclasificar materias de forma automática, una vez se han cumplido los plazos establecidos legalmente.

Pero, sin duda, la condición más determinante para utilizar correctamente los secretos de Estado en los Estados constitucionales -donde rige, con carácter general, el principio de publicidad- es su excepcionalidad. La necesidad de hacer públicas las actuaciones gubernamentales se apoya en el convencimiento de que sin una opinión pública con espíritu crítico y que disponga de una información suficientemente amplia, la subsistencia de la democracia estaría en serio riesgo. Sin publicidad, y sin que se den las condiciones para que la ciudadanía pueda ejercer una función de control efectivo y exigencia de responsabilidades a los organismos públicos ${ }^{11}$, se incurriría en la pura arbitrariedad y el poder se ejercería sin apenas restricciones. La democracia constitucional se encontraría entonces en grave riesgo.

A fin de evitar este desenlace, y para dar cobertura a los secretos de Estado dentro del marco de la democracia constitucional -y de forma compatible con el principio de publicidad-, es preciso llevar a cabo un control jurisdiccional o político -a través de comisiones parlamentarias como la de Secretos Oficiales- de las decisiones declaratorias de dichos secretos. Quizás el defecto más serio del modelo español es que no facilita ejercer un control de los secretos de Estado, y que estos manifiestan una propensión a perpetuarse. Por un lado, la normativa reguladora, vigente desde finales de los años 60, puede calificarse como caduca. Esto no tiene que ver con su origen preconstitucional -pues esta circunstancia no afecta ni positiva ni negativamente a la calidad de su técnica legislativa-, sino que, más bien, se explica porque fue un gobierno autocrático el que aprobó la LSO y su Reglamento. En efecto, los sucesivos gobiernos franquistas mostraron una escasa inclinación a hacer públicas, con luz y taquígrafos, sus actuaciones.

Posteriormente, ya durante la etapa democrática, fueron aprobándose distintas "piezas" de una regulación sectorial cuya aportación fue complicar sumamente y hacer cada vez más disperso el acervo normativo existente. Finalmente, puede afirmarse algo parecido sobre la LTBG de 2013 -a la que ya me he referido antes como una "ocasión perdida"-, que no ha aportado mejoras ni ha ayudado a adaptar

\footnotetext{
11 Según Bobbio (1986: 68), «se ha considerado como uno de los puntos fundamentales del régimen democrático, el que todas las decisiones y, en general, los actos de los gobernantes deban ser considerados por el pueblo soberano. El régimen democrático ha sido definido como el gobierno directo del pueblo o controlado por el pueblo».
} 
el régimen de los secretos de Estado a las necesidades de una democracia del siglo $\mathrm{XXI}$.

\section{Valoración de la regulación española de los secretos de Estado}

Al menos sobre el papel, puede decirse que la LSO de 1968 se atiene a la exigencia de que los secretos de Estado se puedan utilizar solo excepcionalmente, y de que, en todo caso, el principio de publicidad opere como regla general. El art. 1 establece lo siguiente:

«Los órganos del Estado estarán sometidos en su actividad al principio de publicidad, de acuerdo con las normas que rijan su actuación, salvo en los casos en que por la naturaleza de la materia sea esta declarada expresamente "clasificada", cuyo secreto o limitado conocimiento queda amparado por la presente ley».

En la Ley se establece una tipología de materias clasificadas, distinguiéndose entre las secretas y las reservadas. Según el art. 3.1 del Reglamento, son secretas las que

«[...] precisen del más alto grado de protección por su excepcional importancia y cuya revelación no autorizada por autoridad competente para ello, pudiera dar lugar a riesgos o perjuicios de la seguridad del Estado, o pudiera comprometer los intereses fundamentales de la Nación en materia referente a la defensa nacional, la paz exterior o el orden constitucional».

En cambio, las materias reservadas (art. 3.2) hacen referencia a

«[...] los asuntos, actos, documentos, informaciones, datos y objetos no comprendidos en el apartado anterior por su menor importancia, pero cuyo conocimiento o divulgación pudiera afectar a los referidos intereses fundamentales de la Nación, la seguridad del Estado, la defensa nacional, la paz exterior o el orden constitucional».

En realidad, los bienes o intereses jurídicos que se tratan de proteger son los mismos en ambos casos. Las materias secretas y las reservadas únicamente se diferencian porque se atribuye a las primeras una importancia "excepcional", mientras que las segundas son "menos importantes". En el Reglamento no se prevén criterios para determinar cuándo estamos ante materias de una u otra indole (Wilkinson, 2007: 104 y 219), de ahí que la única vía para concretarlo sea a través de una decisión discrecional. En un primer momento, los órganos con competencia para clasificar fueron, exclusivamente, el Pleno del Consejo de Ministros y la Junta de Jefes de Estado Mayor (JUJEM).

Ahora bien, estos órganos no disponen únicamente de la potestad para clasificar materias, sino que, además, son los que pueden cancelar secretos de Estado acordando desclasificaciones- y, cuando fueran solicitados, otorgar permisos de acceso a las materias clasificadas (arts. 7 y 11.2 LSO). Todo esto resulta problemático, 
porque, por un lado, no es sencillo realizar un control de la clasificación, allanándose el camino para que el órgano encargado pase de la discrecionalidad a la arbitrariedad. Y, por otro lado, apenas existen diferencias prácticas entre clasificar materias como secretas o como reservadas, porque, con independencia de la categoría de la clasificación, la prohibición de acceder a ellas seguirá estando vigente mientras que el órgano competente no proceda a su cancelación u otorgue un permiso. En realidad, la única diferencia apreciable entre las materias secretas y las reservadas es que las primeras se encuentran sujetas a condiciones de seguridad y custodia más estrictas que las de las segundas ${ }^{12}$.

Aunque, en un principio, la LSO confiere estas potestades al Pleno del Consejo de Ministros y a la JUJEM, es conveniente hacer dos matizaciones: (i) en 1978, durante la etapa constituyente, las Cortes reformaron la LSO para otorgar acceso al Congreso de los Diputados y al Senado a cuanta información solicitasen, siempre de conformidad con sus reglamentos «y, en su caso, en sesiones secretas» (art. 10.2); y (ii) desde $1984^{13}$, el mando del Ejército vio limitadas de manera drástica sus competencias en lo referente a secretos de Estado, pasando a ser estas meramente consultivas. Como indica Díez Sánchez (1999: 199), el JEMAD no tenía competencia alguna de desclasificación. Además, cuando en 1997 la Sala $3^{a}$ del Tribunal Supremo resolvió el caso de los "papeles del CESID", dictaminó, en las tres sentencias de 7 de abril, que dicha competencia «es la propia de la potestad de dirección política que atribuye al Gobierno el art. 97 CE», con lo cual no puede haber duda de que, en virtud de esa potestad, el Pleno del Consejo de Ministros es el único que puede ejercer competencias de clasificación.

En resumen, las deficiencias de la regulación española de los secretos de Estado se explican, no porque apareciera de forma tardia -en Suecia la primera legislación sobre transparencia data de 1766-, sino porque, cuando al fin se aprobó, las decisiones sobre desclasificación siguieron en manos de las autoridades con potestad clasificatoria. A diferencia de países como Reino Unido, Francia, Italia o EEUU -en los que la desclasificación se produce de forma automática cuando transcurren unos plazos fijados legalmente-, la normativa española no contiene disposiciones en ese sentido, ni se prevé la posibilidad de revisar una clasificación para constatar que subsisten los motivos que la justificaron (Wilkinson, 2007: 105 y 238). Esos plazos no son obligatorios, y mientras no se regulen -como pretende

\footnotetext{
12 En el Reglamento se dispone cómo ha de realizarse la custodia de los materiales secretos (art. 13) y reservados (art. 14), y cómo deben trasladarse (arts. 18 y 19). Estos artículos demuestran que estamos ante una norma de otro tiempo. Según el art. 13, el material secreto «estará guardado en una caja fuerte o armario-archivador a prueba de incendios y dotados de cerraduras de combinación de disco, cuyas dimensiones, peso, construcción e instalación hagan mínimas las posibilidades de robo, violación o indiscreciones». Es indiscutible que urge adaptar esta normativa a las demandas de la era tecnológica.

13 Tras aprobarse la Ley Orgánica 1/1984, de 5 de enero, de reforma de la Ley Orgánica 6/1980, de 1 de julio, por la que se regulan los criterios básicos de la defensa nacional y la organización militar (BOE de 7 de enero de 1984), el mando operativo del Ejército quedó en manos del Jefe del Estado Mayor de la Defensa (JEMAD), desapareciendo la JUJEM.
} 
hacer la Proposición de ley del Grupo Vasco- la única posibilidad que existe de desclasificar materias es mediante un acuerdo del Pleno del Consejo de Ministros, que es el único que cuenta con la potestad requerida. Esta es la razón por la que antes me he referido a España como un país de secretos "eternos", en el que, para impedir que ciertas informaciones sean de dominio público y lleguen a oídos de la ciudadanía, se obstaculiza, con el patrocinio legal, el libre acceso a las mismas.

\section{Algunos mecanismos de ocultación en el derecho español}

Por la forma como está configurado, el sistema español de tratamiento de los secretos de Estado favorece el ocultamiento de los actos del poder estatal. Además, como explicaré a continuación, las posibilidades de encubrir esos actos y de impedir su conocimiento por la opinión pública, se ven incrementadas por causas que en algunos casos tienen origen normativo y en otros se deben a la mala praxis de las autoridades competentes. Seguidamente me referiré a tres de esas causas: a) El abuso de la vía legal en la clasificación de materias; b) La clasificación de materias rebasando los límites establecidos legalmente, sin tener en cuenta las garantías requeridas y actuando el órgano competente desde la arbitrariedad; y c) Aprovechándose de la ampliación, en la LTBG de 2013, del catálogo de materias cuyo acceso puede ser restringido.

\subsection{El abuso de la vía legal en la clasificación de materias}

Mientras que el Pleno del Consejo de Ministros ejerce la competencia de clasificar materias e informaciones concretas, haciendo uso de la legislación se pueden clasificar como secretas o reservadas determinadas materias de forma genérica. En las normas sectoriales hay abundantes ejemplos de ello. En el art. 95.1 de la Ley 58/2003, de 17 de diciembre, General Tributaria, se establece que «Los datos, informes o antecedentes obtenidos por la Administración tributaria en el desempeño de sus funciones tiene carácter reservado». El art. 34.1.i) va incluso más lejos, al reconocer que la reserva de esas informaciones es un derecho de los ciudadanos. Finalmente, tal como se prevé en el art. 116, «La Administración tributaria elaborará anualmente un Plan de control tributario que tendrá carácter reservado, aunque ello no impedirá que se hagan públicos los criterios generales que lo informen».

Otro buen ejemplo de la reserva establecida legalmente lo encontramos en el art. 21.3 de la Ley 3/2015, de 20 de marzo, reguladora del ejercicio del alto cargo de la Administración General del Estado, que establece, a los pocos meses de entrar en vigor la LTBG en diciembre de 2014, el carácter reservado de la información sobre los altos cargos incluida en el Registro electrónico de Bienes y Derechos Patrimoniales.

Finalmente, también por disposición legal tiene carácter secreto casi todo lo relacionado con el Centro Nacional de Inteligencia (CNI). Por citar solo un ejemplo, el art. 3 de la Ley 11/2006, de 6 de mayo, reguladora del Centro Nacional de Inteligencia, establece la previsión de que «El Gobierno determinará y aprobará 
anualmente los objetivos del Centro Nacional de Inteligencia mediante la Directiva de Inteligencia, que tendrá carácter secreto» ${ }^{14}$.

Aunque el recurso a la vía legal para la clasificación de materias es necesario, a mi juicio se ha abusado de ella, pues en algunos sectores que se consideran delicados, la reserva, cuando no el secreto, se han utilizado profusamente, hasta el punto de que han dejado de ser la excepción y se han convertido en la regla. Como observa Díez-Picazo (1998: 81), esto es consecuencia de que las lindes del principio de publicidad no están claramente delimitadas, y da la impresión de que los secretos se protegen en ciertos ámbitos y la publicidad en otros.

\subsection{La clasificación de materias rebasando los límites establecidos legalmente}

La mala praxis gubernamental en las decisiones sobre la clasificación de materias también ha dado lugar a situaciones que, si se generalizaran, serían especialmente preocupantes, debido al uso indebido y abusivo que se hace de los secretos de Estado. Son casos en los que el órgano competente -el Pleno del Consejo de Ministros- ha clasificado materias procediendo de forma arbitraria y soslayando las garantías establecidas legalmente. Un ejemplo muy claro aconteció el 15 de octubre de 2010, cuando en una reunión del Consejo de Ministros, además de tomarse la decisión de clasificar ciertas materias, se declaró secreto el propio Acuerdo de clasificación, que no apareció publicado en el BOE (Malalana Ureña y Moreno Pérez, 2018: 340). En el Acuerdo se clasificaban diecisiete materias, referidas a asuntos como los contactos que estaba llevando a cabo el Estado para liberar a unos cooperantes españoles que habian sido secuestrados en Mali y Somalia, los preparativos para el viaje que el Rey Juan Carlos I realizaría a Chile y a Brasil, las gestiones para apoyar los intereses de la empresa Repsol en Argentina -que no evitaron que dos años después se expropiaran el 51\% de las acciones de su filial, YPF- y la candidatura de quien entonces era Ministro de Asuntos Exteriores, Miguel Ángel Moratinos -que abandonó el puesto una semana después de adoptarse el Acuerdo-, como director general de la FAO. No parece que estas materias puedan comportar un serio riesgo para la seguridad y la defensa.

No es muy alentador pensar que este subterfugio podría emplearse con el propósito de encubrir actuaciones ilegítimas. Como consecuencia de utilizar estas prácticas, el alcance de los secretos de Estado se ha extendido arbitrariamente, dando cobertura a materias cuyo conocimiento puede suponer un menoscabo, no tanto para la seguridad nacional y la defensa, como para el crédito de España en el contexto internacional y en sus relaciones con terceros países. Estas razones se han invocado para evitar desclasificar ciertas materias (Malalana Ureña y Moreno Pérez, 2018: 341).

\footnotetext{
${ }^{14}$ Del CNI sabemos que su directora, con rango de secretaria de Estado, es Paz Esteban López, y poco más. Apenas se conocen datos sobre su estructura interna, organización, medios, instalaciones y actividades, pues esa información está clasificada como secreta. Como indica Carlos Ruiz Miguel (2002: 25-26), en este caso es compresible mantener el secreto, pues el CNI es un servicio de inteligencia. Este autor defiende que en los Estados constitucionales existan y se protejan este tipo de espacios.
} 


\subsection{La ampliación del catálogo de materias que la LTBG permite restringir}

Finalmente, por paradójico que pueda parecer, en la LTBG de 2013 se establece un amplio catálogo de materias cuyo acceso puede ser restringido. Antes de aprobarse la Ley, España era uno de los pocos países de la Unión Europea que no disponían de una ley de transparencia. Los demás eran Chipre, Luxemburgo y Malta. En mi opinión, la LTBG es decepcionante en algunos aspectos. En particular, en lo que afecta a los secretos de Estado, esta Ley no ha contribuido a lograr una mayor garantía de que se satisfagan las exigencias de la publicidad. Por el contrario, se ha incrementado de forma notable el abanico de materias cuyo conocimiento puede ser objeto de restricciones.

Antes de explicar este punto, conviene recordar que entre la publicidad y la transparencia existe una relación estrecha. El principio de publicidad tiene un reconocimiento amplio y está presente en diferentes artículos de nuestra Constitución. El art. 9 se refiere a la publicidad de las normas, pero esta es solo una de las facetas de tan proteico principio. Isabel Lifante (2018: 24) le asigna una función regulativa que tiene una importancia trascendental en los Estados constitucionales. En efecto, la publicidad impone a los poderes públicos ciertas obligaciones y cauces de acción. Sus exigencias son parte del valor de la transparencia, que se sitúa en un nivel más abstracto y contiene otras exigencias y valores que sintonizan con la publicidad (Lifante, 2018: 25), como la veracidad, el libre acceso a la información, etc.

Asi pues, bajo el valor de la transparencia se incluyen otras exigencias que, como la publicidad, son "instrumentales", puesto que cumplen un papel decisivo coadyuvando a la mejora tanto del Estado constitucional como de las instituciones democráticas. Lifante (2018: 26) recuerda que uno de los aspectos positivos de la LTBG es que ha posibilitado un avance en la satisfacción de estas exigencias, mediante la imposición de obligaciones de "publicidad activa" que vinculan a las administraciones. En la exposición de motivos se recalca que

«La presente Ley tiene un triple alcance: incrementa y refuerza la transparencia en la actividad pública -que se articula a través de obligaciones de publicidad activa para todas las Administraciones y entidades públicas-, reconoce y garantiza el acceso a la información -regulado como un derecho de amplio ámbito subjetivo y objetivo- y establece las obligaciones de buen gobierno que deben cumplir los responsables públicos así como las consecuencias jurídicas derivadas de su incumplimiento -lo que se convierte en una exigencia de responsabilidad para todos los que desarrollan actividades de relevancia pública-».

Estas obligaciones de publicidad activa se concretan en el Capítulo II de la LTBG. En él se fijan una serie de instrumentos de control, al tiempo que se especifican unos principios generales y se crea el Portal de Transparencia. También, como novedad importante, por fin se reconoce, en el ordenamiento jurídico español, el derecho de acceso de los ciudadanos a la información pública. Hasta ese momento, nuestra 
Constitución -en el art. 105.b) - se limitaba a incluir una reserva de ley para regular «el acceso de los ciudadanos a los archivos y registros administrativos, salvo en lo que afecte a la seguridad y la defensa del Estado, la averiguación de los delitos y la intimidad de las personas». Es verdad que, en la práctica, el contenido de este artículo ya era interpretado como un genuino derecho de acceso. Pero este no tuvo reconocimiento expreso hasta que el art. 12 LGTB estableció que «todas las personas tienen derecho a acceder a la información pública, en los términos previstos en el art. 105.b) de la Constitución Española, desarrollados por esta Ley $\gg^{15}$.

La paradoja, antes mencionada, de la LTBG reside en que, mientras, por un lado, se reconoce el derecho a acceder a la información pública, del que gozan todas las personas, por otro se recorta el alcance de ese derecho restringiéndolo de forma drástica en algunos casos. Estas restricciones a veces son comprensibles. Unas tienen como razón de ser proteger los datos personales ${ }^{16}$ (art. 15). Otras buscan salvaguardar intereses como la propiedad industrial o el secreto profesional. Y otras, reforzar los bienes jurídicos de la seguridad nacional y la defensa, que son el objeto de la LSO. De forma muy sorprendente, en el articulado de la LTBG no se hace ninguna referencia, ni implícita ni explicitamente, a la LSO, que justifica recurrir a la clasificación de materias para proteger esos intereses vitales. Esto tiene trascendencia desde el punto de vista jurídico, puesto que, si la seguridad y la defensa son amenazadas, la respuesta apropiada desde el Derecho sería efectuando una interpretación sistemática de la LTBG junto a la LSO- que las materias que implican amenaza deberían clasificarse como secretas o reservadas. Por esta razón, la omisión de la LTBG es tan asombrosa, pues da la impresión de que, de repente, la LSO ha desaparecido, como si sus disposiciones ya no estuvieran vigentes en el Derecho español.

Hay que mencionar todavía otras restricciones del derecho de acceso a la información pública que prevé la LTBG. Estas se antojan menos razonables, pues afectan a los intereses económicos y comerciales, la política económica y monetaria, la seguridad pública, las relaciones exteriores y la protección del medioambiente. Son intereses cuya salvaguarda excede el ámbito material de aplicación de la LSO, que se limita a la seguridad nacional y la defensa. Ahora bien, cuando de lo que se trata es de evitar actuaciones indebidas y satisfacer las exigencias de la transparencia -según la pretensión de esta Ley-, las restricciones más preocupantes son, a mi juicio, las que se refieren a «las funciones administrativas de vigilancia, inspección y control» (art. 14.1.g LTBG) y a «la garantía de la confidencialidad o el secreto requerido en procesos de toma de decisión» (art. 14.1.k). La Ley se sirve aqui de un alto grado de indeterminación. Ciertamente, el art. 14.2 dispone que «la aplicación de los límites será justificada y proporcionada a su objeto

\footnotetext{
15 Debe garantizarse el derecho de acceso, no solo a los archivos públicos, sino también a los privados, siempre que tengan relevancia pública (Torres Ventosa, 1998: 365).

${ }^{16}$ En sintonía con los mecanismos de protección que regula la Ley Orgánica 3/2018, de 5 de diciembre, de protección de datos personales y garantía de los derechos digitales.
} 
y finalidad de protección y atenderá a las circunstancias del caso concreto, especialmente a la concurrencia de un interés público o privado superior que justifique el acceso»; pero esto no elimina que con ella en la mano se puede limitar el acceso a la información sobre procesos públicos de decisión ( $v$. $g r$. en licitaciones de obras y servicios públicos, concesión de licencias, etc.) y el control de los mismos. De esta manera, la LTBG permite restringir el conocimiento de informaciones que pueden ser relevantes para la opinión pública, mucho más de lo que permitía hacerlo la LSO. La relación de supuestos afectados se amplía de forma ostensible, mientras se reducen las garantías de salvaguarda del valor de la publicidad, pues no se contempla clasificar esas materias. Llevar a cabo esa clasificación implicaría seguir un procedimiento que, pese a sus defectos y al juicio que antes he hecho de él, está jurídicamente reglado. Finalmente, las limitaciones que establece la LTBG sorprenden todavía más si se tiene en cuenta que uno de los logros de esta Ley es que es proactiva en la imposición de obligaciones de publicidad dirigidas a las administraciones. Por lo demás, no supuso ningún cambio en el régimen jurídico de los secretos de Estado. De ahí que antes la calificara como una "ocasión perdida".

\section{Breve mención a los "papeles del CESID"}

El caso de los "papeles del CESID" fue, sin duda alguna, el más grave en el que se utilizaron los secretos de Estado, a fin de ocultar a la opinión pública ciertos actos del Gobierno en el contexto de la denominada "guerra sucia" contra la banda terrorista ETA. El escándalo se desencadenó a mediados de los años noventa, cuando algunos de estos documentos se filtraron a los medios de prensa. La situación que se generó puso a prueba la integridad de la democracia española.

Aunque el contenido de los documentos apuntaba hacia el Gobierno de Felipe González, cuando en 1996 alcanzó la Presidencia del Gobierno José María Aznar, este se negó a desclasificarlos, a pesar de que habian sido solicitados por las acusaciones del "caso GAL" para utilizarlos como prueba en los procesos penales que se abrieron. Como respuesta, las acusaciones interpusieron tres recursos contencioso-administrativos ante la Sala $3^{\text {a }}$ del Tribunal Supremo, entendiendo que la negativa del Gobierno suponía la vulneración del derecho a la tutela judicial efectiva de los encausados, en su faceta de utilización de todos los medios de prueba pertinentes (art. 24.2 CE). En las tres sentencias de 4 de abril de 1997, la Sala $3^{\text {a }}$ resolvió estimando las pretensiones de las acusaciones y ordenando entregar los documentos a los juzgados para usarlos en la instrucción de los sumarios. En España, aquella fue la primera ocasión en la que se desclasificaron secretos de Estado por orden judicial, de ahí que la doctrina considerara estas sentencias un gran avance.

Aunque en la LSO no se establecen instrumentos de control de los secretos de Estado, para los magistrados de la Sala $3^{\text {a }}$ esto no podía suponer que no existan otras posibilidades de acceder a la justicia. Por otro lado, los actos del Gobierno -v. gr. la decisión de clasificar materias-, igual que los de cualquier otra institución del Estado, pueden ser objeto de control jurisdiccional. En este caso, el acto impugnado limitaba 
de forma injustificada un derecho fundamental. La Sala resolvió llevando a cabo una ponderación de los intereses y derechos afectados: la seguridad del Estado y el derecho a la tutela judicial efectiva en su variante de utilizar los medios de prueba pertinentes. Como señala Díez-Picazo (1998: 73), el criterio que se aplicó fue que, tratándose de delitos graves, la ponderación puede favorecer a los derechos fundamentales aun por encima del interés constitucional en garantizar la seguridad del Estado, que cedería en esa situación.

Aunque las sentencias de la Sala $3^{\text {a }}$ fueron innovadoras, merecen una mención especial los tres autos dictados el 2 de febrero de 1997. En ellos la Sala se dirigió al Gobierno ordenándole que le entregara los documentos para que fueran inspeccionados in camera. Esto significó una gran novedad en nuestro Derecho, pues, aunque en los sistemas anglosajones recurrir a las in camera inspections es algo corriente, en las normas procesales españolas esta posibilidad era ignota y no se contemplaba. El argumento de la Sala fue que para ponderar los intereses comprometidos era necesario que los documentos fueran inspeccionados de forma reservada por los magistrados. Es incuestionable que aquella fue una de esas ocasiones en las que el Derecho avanza siguiendo un genuino impulso creativo judicial.

Asi pues, puede afirmarse que, al menos en el caso más grave de utilización de los secretos de Estado para ocultar actos y decisiones gubernamentales ilegítimas -la información clasificada sobre la organización y funcionamiento de los GAL- que tuvo lugar en nuestro país, el control judicial fue eficaz y proporcionó una solución satisfactoria a tan dificil desafio.

\section{A modo de conclusión: la proposición de ley de reforma de la Ley de Secretos Oficiales}

La Proposición de ley de reforma de la LSO, que ha sido presentada de nuevo -y ya es la cuarta vez consecutiva- en la XIV legislatura ${ }^{17}$ por el Grupo Parlamentario Vasco (EAJ-PNV), supone una oportunidad para revisar los aspectos más caducos de la normativa española en materia de secretos de Estado. Se trata de un texto breve, que cuenta con una exposición de motivos y un solo artículo. La potestad para clasificar materias y declarar secretos de Estado sigue en manos de un órgano colegiado como el Pleno del Consejo de Ministros, que puede hacer uso de ella en régimen de exclusividad. En cambio, es en lo referente a la desclasificación de materias donde se produce un significativo avance, pues se introduce por fin un sistema de plazos. El nuevo art. 4.2 de la Ley quedaría redactado de modo que las materias secretas se desclasificarían de forma automática una vez transcurridos veinticinco años, mientras que las reservadas se desclasifican a los diez. Las materias

${ }^{17}$ El texto se presentó el 13/12/2019. La votación plenaria para la toma en consideración se celebró el 23/06/2020, con el resultado de 197 votos a favor, 53 en contra y 99 abstenciones. Puede consultarse el debate previo en el Diario de Sesiones del Congreso de los Diputados, 31, 23/06/2020: 5-20. 
secretas todavía podrán contar con una prórroga excepcional de diez años más, siempre que la decisión esté convenientemente motivada.

Una vez que las materias secretas o reservadas han cumplido los plazos legales, estas quedarán automáticamente desclasificas (art. 7.1), a no ser que se haya producido una decisión previa del Consejo de Ministros en ese sentido. Además, cuando el Congreso de los Diputados y el Senado tengan acceso a informaciones clasificadas en sesiones que no sean secretas, ello implicará la desclasificación de las mismas (art. 7.2). Finalmente, de acuerdo con el art. 10.2, ambas cámaras podrán acceder a cuanta información soliciten, de conformidad con sus reglamentos. Se elimina del texto la precisión que se hacía en la redacción original: «y, en su caso, en sesiones secretas».

Ahora bien, quizás el punto más reseñable de la Proposición de ley es su disposición transitoria, cuya significación práctica es incuestionable. En ella se determina que todas aquellas materias que, al entrar en vigor la Ley, ya hubieran cumplido los plazos de caducidad del art. 4, quedarán desclasificadas de forma automática. Las que no los hubieran cumplido se desclasificarán en el momento en que lo hagan, sin perjuicio de lo dispuesto en el art. 7. Esto implica que cuando la Ley pase a estar vigente, aquellas materias secretas cuya clasificación se acordó hace al menos veinticinco años, y las reservadas que superen los diez, dejarian de tener esa condición, con lo cual el caudal de informaciones que de improviso sería accesible y susceptible de ser canalizado a la opinión pública, posibilitando su conocimiento, sería inmenso. La preocupación por lo que podría traer consigo aplicar esta disposición transitoria fue, seguramente, una de las razones que explicarian ciertas reticencias hacia la Proposición de ley, que se evidenciaron en las enmiendas presentadas, en la XII legislatura, por algunos grupos parlamentarios ${ }^{18}$.

El porvenir de la Proposición de ley del Grupo Vasco sigue siendo tan incierto en la legislatura actual como lo fue en las anteriores. Por un lado, es suficiente con el acuerdo de solo dos grupos parlamentarios para seguir ampliando sine die el periodo de enmiendas. La concesión de nuevas prórrogas por la Mesa del Congreso de los Diputados es automática, y entre tanto no se requiere la presentación efectiva de enmiendas. En la XII legislatura se concedieron un total de cuarenta y dos ampliaciones, y cuando el trámite fue por fin superado, la Proposición de ley permaneció, durante más de un año, a la espera del informe de la Comisión Constitucional, hasta que caducó al finalizar la legislatura. En la legislatura actual ya se cuentan treinta y ocho ampliaciones, y de momento no se vislumbra la superación

18 El contenido de las enmiendas propuestas puede consultarse en el Boletín Oficial de las Cortes Generales, Serie B, 32-4, 11/04/2018. Los Grupos Parlamentarios Socialista y de Ciudadanos propusieron extender los plazos de vigencia que ya hubieran caducado durante un periodo adicional. Ciudadanos no dudó en justificarlo por «la protección de un interés jurídico superior al del principio de transparencia en la actuación de los poderes públicos, como sin duda lo es el de la Seguridad y el de los intereses de la colectividad nacional», mientras que el Grupo Socialista aludió a que era necesario «establecer un régimen transitorio que asegure la correcta aplicación de la modificación normativa». Véase, sobre las enmiendas presentadas en la XII legislatura, mi trabajo Sendín (2019). 
del trámite de enmiendas. Por otro lado, parece que al Partido Socialista le incomoda la Proposición de ley, y recientemente ha aparecido publicada en la prensa la noticia de que el Gobierno tiene la intención de presentar un proyecto de ley propio para reformar la LSO, que se pretende aprobar en esta legislatura ${ }^{19}$.

A mi modo de ver, no hay demasiados motivos para ser optimista, y pensar que un proyecto de ley del Gobierno, que suponga un avance y una mejora drástica del modelo vigente, podría tener más opciones de ser aprobado que la Proposición de ley del Grupo Vasco. Esta sugiere cambios muy deseables, siendo el más significativo la regulación de un horizonte temporal insuperable de vigencia de los secretos de Estado. Con ello, el tratamiento que estos reciben en el Derecho español se homologaría a los de otros países de nuestro entorno próximo, y se lograría avanzar en la satisfacción del valor de la transparencia. En cualquier caso, es necesario reformar la LSO para disponer de un sistema renovado y sencillo, que sea capaz de superar las carencias de una normativa cuyo tiempo ya ha expirado.

\section{Bibliografía}

ARAGÓN, M. 2006. "Prólogo", en SÁNCHEZ FERRO, S. El secreto de Estado. Madrid: Centro de Estudios Políticos y Constitucionales, pp. XVII-XXIII.

BOBBIO, N. 1985. "La crisis de la democracia y la visión de los clásicos", en BOBBIO, N., PONTARA, G. y VECA, S., Crisis de la democracia. Barcelona: Ariel, pp. 5-25.

BOBBIO, N. 1986. El futuro de la democracia. México D.F.: Fondo de Cultura Económica.

COUSIDO, P. 1995. Comentarios a la ley de secretos oficiales y su reglamento. Barcelona: Bosch.

DEL ÁGUILA, R. 2000. La senda del mal: política y razón de Estado. Madrid: Taurus.

DE LUCAS, J. 1990. "Democracia y transparencia. Sobre poder, secreto y publicidad", Anuario de Filosofía del Derecho, núm. 7: 131-145.

DÍEZ-PICAZO, L. M. 1998. Sobre secretos oficiales. Madrid: Civitas.

DíEZ SÁNCHEZ, J. J. 1999. Razones de Estado y Derecho. Madrid: Tirant lo Blanch.

KANT, I. 2018. Hacia la paz perpetua. Un diseño filosófico. Madrid: Alamanda.

${ }_{19}$ El Pais, 05/04/2021. <https://elpais.com/espana/2021-04-05/el-gobierno-inicia-la-reforma-de-laley-franquista-de-secretos-oficiales.html> [Consulta 05/2021]. 
KELSEN, H. 1968. "Demokratie", en KLECATSKY, H., MARCIC, R. y SCHAMBECK, H. (eds.), Die Wiener Rechtstheoretische Schule. Schriften von Hans Kelsen, Adolf Merkl, Alfred Verdross (2). Wien: Europa Verlag, pp. 1743-1776.

KELSEN, H. 2006. "Verteidigung der Demokratie", en JESTAEDT, M. y LEPSIUS, O. (eds.), Verteidigung der Demokratie. Tübingen: Mohr Siebeck, pp. 229-237.

LIFANTE VIDAL, I. 2018. Lo público y lo privado. Buenos Aires: B de f.

MALALANA UREÑA, A. y MORENO PÉREZ, L. 2018. "La Ley de Secretos Oficiales, lastre para la investigación histórica", Ayer, núm. 110, 2: 333-347.

RUIZ MIGUEL, C. 2002. Servicios de inteligencia y seguridad de Estado constitucional, Madrid: Tecnos.

SÁNCHEZ FERRO, S. 2006. El secreto de Estado. Madrid: Centro de Estudios Políticos y Constitucionales.

SENDÍN MATEOS, J. A. 2019. "El conflicto entre publicidad y secretos de Estado: la proposición de Ley de reforma de la Ley 9/1968, de 5 de abril, sobre Secretos Oficiales", en GARCIA AMADO, J. A. (coord.), Conflictos de Derechos. Problemas teóricos y supuestos prácticos. Valencia: Tirant lo Blanch, pp. 177-205.

SENDÍN MATEOS, J. A. 2020. "Secreto de Estado", Eunomía. Revista en Cultura de la Legalidad, núm. 18: 258-273.

TORRES VENTOSA, J. J. 1998. "La regulación legal de los Secretos Oficiales". Anuario de la Facultad de Derecho de la Universidad de Extremadura, núm. 16: 357-387.

WILKINSON, H. 2007. Secretos de Estado y Estado de Derecho: régimen jurídico de los secretos oficiales en España. Barcelona: Atelier. 